\title{
Psychometric Properties of the Big Five - Children Questionnaire, Russian Version
}

\author{
Sergey Malykh ${ }^{1}$, Georgy Vasin $^{1}$, Ivan Voronin ${ }^{1}$, and Tatiana Tikhomirova ${ }^{1, *}$ \\ ${ }^{1}$ Psychological Institute of Russian Academy of Education, 125009 Moscow, Russia
}

\begin{abstract}
Studying personality traits in children and adolescents is valuable, because they can predict a number of important outcomes. The Big Five Questionnaire - Children (BFQ-C) is a questionnaire for 9-14 year-olds used to measure the Big Five personality traits. No analogous psychometric instruments exist or Russian-speaking children of this age group, so our goal was to adapt it into Russian and assess the psychometric properties of the adapted version of the questionnaire. We show evidence of adequate factorial validity and internal consistency of the adapted version in two groups of school-age Russian students.
\end{abstract}

\section{Introduction}

Use A4 paper size $(210 \times 297 \mathrm{~mm})$ and adjust the margins to those shown in Table 1. The final printed area will be $172 \times 252 \mathrm{~mm}$.

The 5-factor structure of personality, or Big Five, is one of the few well-replicated constructs in psychology today. This structure has been observed in child and adult samples from many different cultural backgrounds [1-6]. Even though the names of some of the factors may differ between studies [7], the 5 factors are generally referred to as Neuroticism, Extraversion, Openness, Agreeableness, and Conscientiousness [8].

The Big Five factors are broad and their exact composition is still up for debate, however a set of lower order factors, or facets, can be identified. For Neuroticism they are anxiety, impulsivity, reflectiveness and fragility. Extraversion includes sociability, activity level and positive emotionality. Openness is comprised of imagination, creativity and open-mindedness. Agreeableness includes trust, altruism, straightforwardness and humility. Finally, the facets of Conscientiousness are competency, orderliness, selfdiscipline and a drive towards accomplishment.

The Big Five has been very popular with researchers and a number of questionnaires have been developed to measure it. In Russian-speaking populations the most popular questionnaire is the NEO-PI-R [8], adapted into Russian by V.E. Orel and I.G. Senin [9]. This questionnaire was designed to measure personality traits in adults and adolescents, but is unsuitable for younger adolescents and children [9].

This leaves researchers without a measurement instrument to study the Big Five personality traits in Russian-speaking children. At the same time studies show that personality traits can predict several important outcomes in school-age children - from academic achievement to behavioral problems [10-12].

The Big Five Questionnaire - Children (BFQ-C) is a self-reported phrase-based questionnaire used to measure personality traits in children from 9 to 14 years old [13]. It was developed by Barbaranelli and colleagues in 2003, the original version was in Italian, and an English version was later created by the same authors. The aim of our study is to adapt the English version of BFQ-C for Russian-speaking populations. In order to study the psychometric properties of the translated Russian version of the questionnaire, we assessed the factor structure of the questionnaire and the internal consistency of its scales in a sample of school-age children.

\section{Methods}

\subsection{Participants}

The sample included 250 students from Primary school (Grades II-IV, mean age 9.47 years, $\mathrm{SD}=0.64$ years, $51 \%$ were female) and 280 students from Secondary school (Grades VI-VIII, mean age 13.21 years, $\mathrm{SD}=1.31$ years, $53 \%$ were female). For all participants the informed consent of a parent was provided. The data were collected anonymously; each participant was assigned with a unique ID.

\subsection{Measures}

The original version of the "Big Five Questionnaire Children Version" (BFQ-C) comprises 65 sentences apprehensible for children [13]. The authors report satisfactory psychometric properties of BFQ-C. Factor analysis exposed five factor structure-corresponding to the "Big Five" personality traits-in both Primary school

* Corresponding author: tikho@mail.ru 
and Secondary school students. All scales also showed moderate consistency across the report types (child report, mother report, teacher report).

In the original BFQ-C the scales quantify the Big Five personality traits: Extraversion, Neuroticism, Openness, Agreeableness, and Conscientiousness. Each scale is measured with 13 items. Each item is a sentence which expresses behavior. The participants have to rate to what extent the sentence describes their behavior using either 3-point or 5-point Likert scale, depending on age. The sentences were translated by the members of the Laboratory of the Developmental Behaviour Genetics, Psychological Institute of Russian Academy of Education, Moscow. The Russian translation of the sentences was then checked by reverse translation.

The Extraversion scale assesses the level of activity and self-assurance ("I like to joke"). The Neuroticism scale measures emotional instability, anxiety, discontent, and anger ("I easily get angry"). The Openness scale reflects the breadth of interests, the ability to search and adopt new knowledge, the creativity ("I easily learn what I study at school"). The Agreeableness scale indices empathy, helpfulness and care ("I trust in others"). The Conscientiousness evaluates self-discipline, punctuality and responsibility ("I play only after I have finished my homework").

A confirmatory factor analysis was used to study the factor structure of BFQ-C. We fit the model with five latent factors (corresponding to the Big Five traits) and 65 observed variables (the items). Each factor was associated with 13 items according to the original factor structure of BFQ-C. The model included 335 free parameters in total.

The model parameters were computed by means of WLSMV estimator which shows best performance on the ordinal data [14]. We used the following criteria of model fit: Comparative Fit Index (CFI), Tucker-Lewis Index (TLI), Root Mean Square Error of Approximation (RMSEA), and Weighted Root Mean Square Residual (WRMR). CFI and TLI $>0.9$, RMSEA $<0.05$, and WRMR close to 1 index the good model fit [15].

We computed Cronbach alpha and split-half reliability with Spearman-Brown correction as the indices of scale reliability. The values over 0.6 were considered sufficient and over 0.7 - satisfactory. The computations were performed using Mplus.

\section{Results}

\subsection{Factor structure of questionnaire}

After fitting the five factor model three items were removed: items 39 and 56 showed reverse factor loadings, and the factor loading of item 9 was statistically non-significant. The result was replicated in both age groups. These 3 items were removed from further analysis. The final model included 5 latent factors, 62 observed variables (items), 320 free parameters in total.

The fit indices of the model are reported in the Table 1. The fit indices obtained in two age groups are highly similar. The model shows tolerable fit according to RMSEA (0.031 and 0.045). CFI and TLI do not reach the critical level, however similar values were reported in the study of original BFQ-C (0.87 and 0.90 , for details see [13]).

Table 1. The fit indices of the BFQ-C five factor model

\begin{tabular}{|l|c|c|c|c|}
\hline & CFI & TLI & RMSEA & WRMR \\
\hline Primary school & 0.86 & 0.86 & 0.031 & 1.1 \\
\hline $\begin{array}{l}\text { Secondary } \\
\text { school }\end{array}$ & 0.86 & 0.86 & 0.045 & 1.4 \\
\hline
\end{tabular}

CFI = Comparative Fit Index, TLI = Tucker-Lewis Index, RMSEA = Root Mean Square Error of Approximation, $W R M R=$ Weighted Root Mean Square Residual

\subsection{Analysis of reliability}

The reliability indices are reported in Table 2,3. On the sample of the Secondary school students all scales showed high reliability (0.7-0.8). In Primary school all scales showed high reliability (up to 0.84) except Extraversion (Cronbach $\alpha=0.60$ and split-half reliability $=0.64)$.

Table 2. The reliability indices of the BFQ-C scales

\begin{tabular}{|l|c|c|}
\hline \multicolumn{1}{|c|}{ Scale } & \multicolumn{2}{|c|}{ Primary school } \\
\hline & Cronbach $\alpha$ & Split-half \\
\hline Extraversion & 0.60 & 0.64 \\
\hline Agreeableness & 0.75 & 0.72 \\
\hline Conscientiousness & 0.77 & 0.75 \\
\hline Neuroticism & 0.84 & 0.84 \\
\hline Openness & 0.70 & 0.72 \\
\hline
\end{tabular}

Table 3. The reliability indices of the BFQ-C scales

\begin{tabular}{|c|c|c|}
\hline \multirow{2}{*}{ Scale } & \multicolumn{2}{|c|}{ Secondary school } \\
\cline { 2 - 3 } & Cronbach $\alpha$ & Split-half \\
\hline Extraversion & 0.76 & 0.72 \\
\hline Agreeableness & 0.72 & 0.78 \\
\hline Conscientiousness & 0.80 & 0.76 \\
\hline Neuroticism & 0.80 & 0.79 \\
\hline Openness & 0.74 & 0.73 \\
\hline
\end{tabular}

\section{Discussion}

In this study we aimed to adapt the BFQ-C for Russian-speaking children. We translated the items, tested them on a sample of Russian-speaking children and assessed the psychometric properties of the Russian version of the questionnaire. Based on our results, the Russian version of the BFQ-C is adequate for measuring the Big Five personality traits in Russian-speaking children between 9 and 14 years old. We have observed the intended 5-factor structure of the original in the adapted version. The scales are sufficiently internally consistent. Unfortunately we could not study the convergent validity of the adapted version's results, because no analogous questionnaires are currently available in Russian.

In summation, the BFQ-C Russian version is reliable instrument with adequate factorial validity, when used to 
study the Big Five personality traits in 9-14 year old children.

This study was supported by the grant from the Russian Science Foundation [grant RSF № 14-18-03764].

\section{References}

1. D.W. Fiske, Journal of Abnormal and Social Psychology, 44, 3 (1949)

2. W.T. Norman Journal of Abnormal and Social Psychology, 66, 6 (1963)

3. R.R. McCrae, P. Costa., T.A. Martin et al., Journal of Research in Personality, 38, 2 (2004)

4. M.J. McLarnon, J.J.Carswell, Personality and Individual Differences, 54, 5(2013)

5. E.S. Nizamova, M.V. Ptukha, M.M. Lobaskova, Teoreticheskaya i eksperimentalnaya psikhologiya, [Theoretical and experimental psychology], 6,4, (2013)

6. S.B. Malykh, I.A. Voronin, V.I. Ismatullina, I.M. Zakharov, T.N. Tikhomirova, Teoreticheskaya i eksperimentalnaya psikhologiya, [Theoretical and experimental psychology],7,4, (2014)

7. S.B. Malykh, T.N. Tikhomirova,Voprosy Psychologii [Question of Psychology], 2, (2015)

8. P.T. Costa, R.R.McCrae. Professional manual. Odessa, FL: Psychological Assessment Resources, (1992)

9. V.Orel,I.Senin, Manual, Yaroslavl, (2008)

10. P.Leeson, J.Ciarrochi, P.Heaven, Personality and Individual Differences. 45, (2008)

11. N.Kuncel, S. Hezlett, D.Ones, Journal of personality and social psychology, 86,1, (2004)

12. T.Chamorro-Premuzic, A.Furnham, Journal of Research in Personality, 37, 4, (2003)

13. C.Barbaranelli, G.Caprara, A.Rabasca, C.Pastorelli, Personality and Individual Differences, 34, (2003)

14. C.-Y.Yu \& B.Muthén, Paper presented at the annual meeting of the American Educational Research Association, New Orleans, LA. (2002)

15. C.Geiser, Data Analysis with Mplus, New York: Guilford, (2012). 